\title{
Analysis of land use dynamic econometric change in Chaohu basin from 2000 to 2015
}

\author{
Zhong Yong, Feng Shaoru, Huang Muyi* Zhao Qiang, and Zhang Jiahui \\ Department of Environmental Engineering, Anhui Jianzhu University, 230601, Hefei, P. R. China
}

\begin{abstract}
Chaohu basin is located in the central economic belt, as an important part of the Yangtze River Basin. Based on the data of land use classification from 2000 to 2015, this paper makes a dynamic econometric analysis on the spatial structure of land use in Chaohu basin. The results show that: (1) The agricultural land has been in a downward trend from 2000 to 2015 . However, the construction land has been increasing. From 2005 to 2010, the change of agriculture and the construction land have reached the maximum value, which are $-0.279 \%$ and $1.814 \%$, respectively. (2) During $2000-2015$, every five years, the change of land use degree in Chaohu basin is greater than 0 . The land use in the study area is in the development period, among which the change of land use from 2000 to 2005 is the largest. (3) The information entropy of land use in Chaohu basin is more than 1, and the change of information entropy is more than 0 , which indicates that the information entropy is on the rise and the land use is in disorder. The results are of practical significance to the ecological security and optimal regulation of Chaohu Basin.
\end{abstract}

\section{Introduction}

Land is the basis of ecological environment and the carrier of sustainable development of social economy. Land use structure refers to the proportion relationship between the area of land and the type of land use in a region ${ }^{[1]}$. The change of land use structure is an important reason for the change of regional ecosystem, and also the main driving force for the effect of ecological environment. Chaohu basin is an economically developed area in Anhui province, which is also an important part of the Yangtze River Basin. In recent years, the social and economic development of Chaohu basin is rapid, the population growth is fast, and human activities are concentrated, which has a strong impact on the land use structure of the basin. Chaohu basin water environment protection area is divided into three levels ${ }^{[2]}$. At present, the water ecological management mode based on the water environment ecological protection zone has gradually developed into an international research hotspot, and has been applied to the daily water resource management by relevant government departments, and has gradually become a common basic unit of international water resource management [3]. Many scholars have used various methods to study the spatial structure of land use and its spatiotemporal dynamic change in different regions. It is of great significance to strengthen the land use change in the water environment ecological function area and reveal the temporal and spatial characteristics of the land use change for the regulation and optimization of the land ecosystem function in the water environment core area. The ecological function of Chaohu Basin and the degree of land use change directly affect the water ecological health of Chaohu Lake. In this paper, the dynamic econometric analysis of the spatial structure of land use in Chaohu basin is carried out from different perspectives, in order to provide a scientific basis for the ecological security and optimal regulation of land in Chaohu basin.

\section{Research area and data processing}

\subsection{Overview of the study area}

Chaohu basin is located in the middle of Anhui province and the lower reaches of the Yangtze River Basin. In 2013, Chaohu basin was listed as one of the first batch of national ecological civilization demonstration areas. The administrative divisions involve 11 counties, districts of Hefei City, Lu'an City and Chaohu City. The total area of basin is about $14000 \mathrm{~km}^{2}$. The terrain is high in the south and low in the north. There are 33 rivers of different sizes around Chaohu Lake ${ }^{[4]}$. Chaohu basin is an important economic engine for the development of eastern China's Anhui Province and even the central China economic zone. The whole region is an important water source and ecological protection area in China, and is the core area for the integrated development of Anhui provincial capital economic circle, Hefei metropolitan circle and Wanjiang urban belt. In the planning of national main functional area and national ecological functional zoning, it is not only a key development area, but also an important ecological functional area, which is the most contradictory area in

\footnotetext{
$\overline{{ }^{*} \text { Corresponding author: huangyang78@ } 163 . c o m}$
} 
the spatial allocation of land and resources. The location of the study area is shown in Figure 1.



Fig. 1. Topography and scope of Chaohu Basin

\subsection{Data source and processing}

Based on the Landsat TM in 2000, ETM+ in 2005 and 2010 and Landsat-8/OLI image in 2015 (mainly select the image data with clear and low cloud and good quality from June to September, and use UTM projection to unify to WGS-84 coordinate system), land use classification is carried out by supervision classification method according to the land resource classification system "LUCC classification system" of Chinese Academy of Sciences. The main processing includes: firstly, ERDAS was used to carry out geometric correction, correction, splicing, histogram matching, fusion and other image pre-processing for the four phases of remote sensing images in 2013. Secondly, the vector boundary of Chaohu basin is used to extract the remote sensing images of the spliced study area. Finally, ERDAS 2013 is applied to establish the training samples in the study area by visual inspection until the separability is more than 1.9. The results of each period were calculated by confusion matrix, and the kappa coefficient was above 0.75 , which met the research requirements.

\section{Research methods}

\subsection{Dynamic degree of land use}

In this paper, the spatial structure of land use in Chaohu basin is analyzed from the dynamic perspective by using three methods of quantitative geographical analysis. The dynamic degree formula of land use is as follows ${ }^{[5]}$ :

$$
K=\frac{U_{b}-U_{a}}{U_{a} \times T} \times 100 \%
$$

Where, $K$ is the dynamic degree of a certain land use type in the study period; $U_{a}$ and $U_{b}$ are the number of a certain land use type at the beginning and end of the study period respectively; $T$ is the study duration. When $T$ is year, $K$ is the annual change rate of a certain land use type in the study area.

\subsection{Comprehensive index analysis of land use degree}

The calculation formula of land use comprehensive degree index is ${ }^{[6]}$ :

$$
\begin{gathered}
L=100 \times \sum_{i=1}^{n} A_{i} \times C_{i} \\
\mathrm{~L} \in[100,400]
\end{gathered}
$$

In the formula (2), $L$ is the comprehensive land use index; $A_{i}$ is the class $i$ land use classification index, according to the land use analysis and evaluation standard $^{[6]}$ proposed by Zhuang Dafang and Liu Jiyuan, that is, 3 for agricultural land, 2 for forest land, grassland and water area, and 4 for construction land; $C_{i}$ is the ratio of the class $i$ land area and the total land area of the study area. According to the formula [7], the comprehensive index of land use ranges from 100 to 400, and the size of the comprehensive index can reflect the level of land use.

$$
\Delta L_{b-a}=L_{b}-L_{a}=\left[\sum_{i=1}^{n}\left(A \times C_{i b}\right)-\sum_{i=1}^{n}\left(A \times C_{i a}\right)\right] \times 100
$$

In the formula (3), $L_{b}$ and $L_{a}$ respectively represent the comprehensive index of land use degree in $b$ time and a time study area; $a$ is the number of grade $i$ land use classification; $\mathrm{C}_{i b}$ and $\mathrm{C}_{i a}$ are the ratio of grade $i$ land area in $b$ time and $a$ time to the total land area in study area. If $\Delta L_{b-a}>0$, the land use of the study area is in the development period, otherwise it is in the recession or adjustment period.

\subsection{Information entropy analysis of land use}

The entropy of land use information can reflect that the whole land use of Chaohu basin is in a state of disorder, adjustment or stability. The calculation formula is as follows ${ }^{[8]}$ :

$$
\begin{gathered}
H=-\sum_{i=1}^{n} P_{i} \ln P_{i} \\
P_{i}=\frac{A_{i}}{A}
\end{gathered}
$$

The change of information entropy is as follows:

$$
\Delta H_{b-a}=H_{b}-H_{a}
$$

In the formula (4), $P_{i}$ refers to the ratio of the $i$ type of land use to the total land area of the study area, and in the formula (6), $\Delta H_{b-a}$ is the difference of information entropy between $\mathrm{b}$ and a year. When $\Delta H_{b-a}>0$, the change of land use in the study area is disordered, otherwise it is orderly.

\section{Results and analysis}

\subsection{Analysis of land use dynamic change in Chaohu Basin}

Combined with the landscape characteristics of the basin, the study is divided into five land types. From the Figure 2 , we can see the area change of land use types in Chaohu basin. 




Fig. 2. Analysis of land use annual dynamic change index of Chaohu Basin from 2000 to 2015.

The results of dynamic change of land use are shown in Figure 2. During the stage of 2000-2015, agricultural land has been on a downward trend with a maximum decrease of $0.279 \%$. During the next stage of 2010-2015, agricultural land has been reduced by $0.259 \%$. It shows that with the acceleration of urbanization, some agricultural land has been occupied. The result of dynamic degree calculation (Fig. 2) shows that in the past 15 years, the construction land in Chaohu Basin has increased most severely, with the highest dynamic degree being $1.814 \%$, and the decrease of agricultural land is the most severe, with a dynamic degree of $0.279 \%$. This indicates that the expansion of construction land in Chaohu basin has occupied a lot of farmland in the past 15 years. From the perspective of the whole basin, among all kinds of land types, only farmland, woodland and grassland have negative change rates of land use dynamic degree, which are $-0.259 \%$, $0.034 \%$ and $-0.003 \%$, respectively. On the whole, the construction land has been increasing from $1.009 \%$ in the stage of $2000-2005$ to $1.814 \%$ in the next stage of 2005-2010. The growth rate has continued to increase from 2010 to 2015, but the absolute increase is still growing rapidly, which is consistent with the development trend of urban construction in Chaohu basin. The growth rate of grassland is the largest in the stage of 2010-2015, which is consistent with the efforts of Chaohu basin in recent years to focus on urban greening and improve the ecological environment.

\subsection{Analysis of land use comprehensive index change in Chaohu Basin}

The analysis of land use degree in Chaohu basin can not only reflect the depth and breadth of land use, but also reflects the natural attributes of land use in the water environment protection area, which is very helpful to understand the land use situation at that time. As shown in the calculation results of land use index (Table 1), the land use comprehensive index of Chaohu basin in 2000 was 285.0769, 285.4887 in 2005 and 286.3491 in 2010, 287.1439 in 2015 , respectively. In the past 15 years, the index of land use degree has not changed much, but decreased by 2.0670 .

As shown in the calculation results of land use index (Table 1), the change of land use degree can quantitatively express the comprehensive level and change trend of land use in the study area. The calculation result $\Delta L_{b-a}>0$ indicates that the land use degree of Chaohu Basin is in the development period in the past 15 years, and the land use degree of Chaohu Basin has the trend of strengthening constantly.

In the formula (3), $L_{b}$ and $L_{a}$ respectively represent the comprehensive index of land use degree in $b$ time and $a$ time study area; $a$ is the number of grade $i$ land use classification; $C_{i b}$ and $C_{i a}$ are the ratio of grade $i$ land area in $b$ time and $a$ time to the total land area in study area. If $\Delta L_{b-a}>0$, the land use of the study area is in the development period, otherwise it is in the recession or adjustment period.

According to the land use comprehensive index in different time, the change of land use degree in different development stages of watershed can be calculated, so as to reflect the change of land use degree in different development stages of watershed. The calculation process is as follows:

2000-2005 stage:

$\Delta L_{b-a}=L_{2005}-L_{2000}=285.4887-285.0769=0.4118$

2005-2010 stage:

$\Delta L_{b-a}=L_{2010}-L_{2005}=286.3491-285.4887=0.8604$

2010-2015 stage:

$\Delta L_{b-a}=L_{2015}-L_{2010}=287.1439-286.3491=0.7948$

Table 1. Analysis of land use comprehensive index and its change amount of Chaohu Basin from 2000 to 2015.

\begin{tabular}{|c|c|c|c|c|}
\hline \multirow{2}{*}{} & \multicolumn{4}{|c|}{ Year } \\
\cline { 2 - 5 } & 2000 & 2005 & 2010 & 2015 \\
\hline $\begin{array}{c}\text { Land use } \\
\text { comprehensive index } \\
(\mathrm{L})\end{array}$ & 285.0769 & 285.4887 & 286.3491 & 287.1439 \\
\hline $\begin{array}{c}\text { Change of land use } \\
\text { comprehensive index } \\
(\Delta \mathrm{L})\end{array}$ & 0.4118 & 0.8604 & 0.7948 \\
\hline
\end{tabular}

\subsection{Analysis on the change of land use information entropy in Chaohu Basin}

The information entropy of land use can reflect the disorder, adjustment or stability of land use in Chaohu watershed. From the calculation result of land use information entropy in Chaohu basin, it can be seen that the land use information entropy in the Chaohu basin is more than 1 between 2000 and 2015 (Table 2). Among them, the land use information entropy in 2000 was the lowest, which was $1.0886,1.0989$ in 2005 and 1.1160 in 2010 and 1.1311 in 2015, which was the largest, indicating that the land use information entropy in Chaohu basin has been on the rise. The index of land use information entropy can reflect that the land use of Chaohu basin has been in an active stage, and the change amount of information entropy $\Delta H$ is greater than 0 , which is in a state of disorder. The information entropy shows an upward trend, the disorder degree of land is increasing, and the upward trend is relatively stable. From the change of information entropy, the change from 2000 to 2005 is 0.0103 , the change from 2005 to 2010 is 0.0171 , and the change from 2010 to 2015 is 
0.0151, on the whole, the information entropy shows an upward trend, but the growth shows a trend of first rising and then falling. It is predicted that the disorder of land use will last for a long time. The information entropy of land use increases and the whole land use tends to be disordered, which indicates that the land use type is in the adjustment period ${ }^{[9]}$.

Table 2. Analysis of land use information entropy and its change amount of Chaohu Basin from 2000 to 2015.

\begin{tabular}{|c|c|c|c|c|}
\hline \multirow{2}{*}{} & \multicolumn{4}{|c|}{ Year } \\
\cline { 2 - 5 } & 2000 & 2005 & 2010 & 2015 \\
\hline $\begin{array}{c}\text { Land use } \\
\text { information } \\
\text { entropy } \\
(\mathrm{H})\end{array}$ & 1.0886 & 1.0989 & 1.1160 & 1.1311 \\
\hline $\begin{array}{c}\text { Change of } \\
\text { information } \\
\text { entropy } \\
(\Delta \mathrm{H})\end{array}$ & 0.0103 & 0.0171 & 0.0151 \\
\hline
\end{tabular}

\section{Conclusion and discussion}

Through the quantitative analysis of the spatial structure of land use in Chaohu basin from 2000 to 2015, it can be seen that there are some differences in the spatial structure of land use in Chaohu basin, which is basically consistent with the actual situation, indicating that the land use data and calculation model adopted in this paper can better reflect the spatial structure of land use in a certain research area.

The results show that: (1) the agricultural land has been in a downward trend from 2000 to 2015 . However, the construction land has been increasing, among which, from 2005 to 2010, the decrease of agriculture and the increase of construction land have reached the maximum value, which are $0.279 \%$ and $1.814 \%$, respectively, which is consistent with the development trend of urban construction in Chaohu basin. (2) During 2000-2015, every five years, the change of land use degree in Chaohu basin is greater than 0 , and the change of land use comprehensive index shows a trend of first rising and then falling. The land use is in the development period in the study area, among which the change of land use in the stage of 2000-2005 is the largest, and the change of land use in the next stage of 2010-2015 is declining. (3) The information entropy of land use in Chaohu basin is more than 1 , and the change of land use information entropy is more than 0 , which indicates that the information entropy is on the rise and the land use is in disorder. The results are of practical significance to the ecological security and optimal regulation of Chaohu Basin. The calculation and analysis of land use degree index show that the intensive conversion of land use degree area of different grades shows that the land use degree of the basin has the trend of strengthening continuously, indicating that the land use of the study area is in the development period. The analysis of the change of land use information entropy in Chaohu basin shows that the information entropy is on the rise, and the disorder of land use in Chaohu basin will last for some time. The dynamic change of land use reflects the hot spots of the impact of human activities and economic development on land use in Chaohu basin. In the future, we will further explore how to effectively plan and strengthen the rationality and security of land use in policy, so as to provide scientific basis for the rational use of land resources in Chaohu basin and the formulation of regional sustainable development strategy.

\section{Acknowledgements}

This research was funded by the Major Research Project of Humanities and Social Sciences in Colleges and Universities of Anhui Province (No. SK2018ZD043), and the Science and Technology Innovation Strategy and Soft Science Research Project of Anhui Province (No. 201806a02020046).

\section{References}

1. Y.N. Gao, J.F. Gao, Y. Xu, Journal of natural resources, 25(2010)

2. Z.M. Zhang, J.F. Gao, R.H. Yan, Resources and environment of Yangtze River Basin, 7(2015)

3. Y.N. Gao, J.F. Gao, D.F. Chen, et al. Geographic research, 31 (2012)

4. Y.J. Zhang, S. Chen, J.C. Xiang, Yangtze River Resource basin and environment, 20 (2011)

5. H.Z. Wang, R.D. Li, H.H. Wu, Remote sensing of land and resources, 52 (2002)

6. D.F. Zhuang, J.Y. Liu, Journal of natural resources, 12 (1997)

7. X.F. Li, L.M. Liu, X. Qi, et al. Chinese Journal of Applied Ecology, 25(2014)

8. Y.G. Chen, J.S. Liu, Geographic research, 5(2001)

9. P.J. Shi, X.B. Zhang, J. Luo, Soils, 43(2011) 